\title{
Conservative Approach for replacing missing Tooth using Glass Fiber-reinforced Composite
}

\author{
${ }^{1}$ Sadhana A Raina, ${ }^{2}$ Priyanka Khode, ${ }^{3}$ Manjusha M Warhadpande
}

\begin{abstract}
The loss of anterior tooth can be hurtful to the patient both psychologically and socially. In adolescent patients, temporary replacement of teeth can minimize these concerns. Many approaches have been described for this temporary replacement. Adhesively luted, fiber-reinforced retained fixed partial denture (FPD) can be a clinical alternative for the replacement of missing anterior tooth in selective situations. This is an innovative alternative to conventional metal, ceramic restoration. It is especially useful for patients who cannot afford high cost of FPD and cannot devote much time (number of sittings) for the treatment. The main advantage of fiber-reinforced composite fixed prosthesis is conservative cutting of tooth. Structure and chairside fabrication of the bridge using acrylic tooth are less expensive for the patients. The purpose of this clinical study is to evaluate the clinical usefulness of the fiber-reinforced composite FPD. This report describes the clinical treatment of patients using fiber-reinforced composite.
\end{abstract}

Keywords: Acrylic tooth, Conservative approach, Fiberreinforced composite, Flowable composite resin.

How to cite this article: Raina SA, Khode P, Warhadpande MM. Conservative Approach for replacing missing Tooth using Glass Fiber-reinforced Composite. Int J Prosthodont Restor Dent 2016;6(2):47-49.

\section{Source of support: Nil}

\section{Conflict of interest: None}

\section{INTRODUCTION}

In most of the patients who cannot afford the high cost of fixed prosthesis or cannot give a lot many sittings to the dentists, but still desire an instant fixed prosthesis with the most conservative approach, fiber-reinforced composite is the best option.

It is a conservative and innovative approach to conventional fixed restorations. Young patients having edentulous space no wider than one or two teeth are the best candidates for fiber-reinforced composites.

\footnotetext{
${ }^{1}$ Assistant Professor, ${ }^{2}$ Intern, ${ }^{3}$ Professor

${ }^{1-3}$ Department of Conservative Dentistry and Endodontics Government Dental College \& Hospital, Nagpur, Maharashtra India

Corresponding Author: Sadhana A Raina, Assistant Professor Department of Conservative Dentistry and Endodontics Government Dental College \& Hospital, Nagpur, Maharashtra India, Phone: +919423685967, e-mail: drsadhanaraina@ gmail.com
}

\section{Fiber-reinforced Composites}

Various therapeutic solutions can be used to replace a single anterior missing tooth. ${ }^{1}$ The development of implant-supported restorations led to a more conservative approach to single tooth replacement. However, some patients reject this therapeutic opinion either because of high cost or fear of surgery. Systemic problems may also contraindicate surgery. ${ }^{2}$

With the advent of adhesive dentistry, clinicians and researchers investigated the embedding of reinforcement material into composite resin and found that they provide an increase in certain physical properties and are more durable tooth stabilizations. Various dental procedures, such as tooth splinting, orthodontic retentions, and replacement of missing tooth have been carried out by using fiber-reinforced composite resin. ${ }^{3}$

Tooth-colored materials, such as all ceramics or fiber-reinforced composites, in addition to conventional metal-based systems are recommended to withstand mastication loads. Fiber-reinforced composites contribute to the positive esthetics of the restoration and avoid the discoloration of the gingiva caused by metallic systems.

Recently, the use of fiber-reinforced composite is as another type of resin-bonded fixed partial denture (FPD). Factors affecting the durability of fiber-reinforced composites include the properties of fibers; matrix and polymers; impregnation of fibers with resin; adhesion of fibers to the matrix; quantity of fibers; and the direction, orientation, location, construction, distribution, and position of fibers.

Because of their ease of handling and physical characteristics, these glass fibers are very useful for the fiberreinforced composite fixed prosthetic restorations. ${ }^{4}$

The case reports presented in this article demonstrate chairside fabrication of fiber-reinforced FPD using impregnated glass-woven fiber to reinforce flowable composite resin.

\section{CASE REPORTS}

\section{Case 1}

A female patient aged 26 years reported to the Nagpur Government Dental College and Hospital with a complaint of missing right central incisor. When she was explained about conventional fixed partial prosthesis, in 

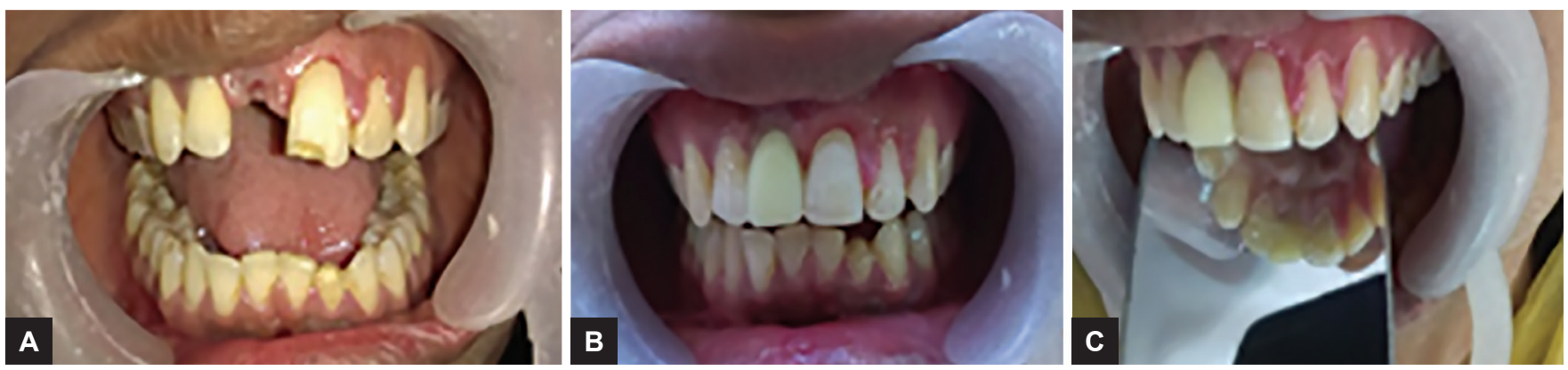

Figs 1A to C: $(A)$ Before treatment; $(B)$ after treatment; and $(C)$ palatal view

which her adjacent teeth will be trimmed for making a bridge, the patient refused to undergo crown cutting of the natural teeth. Under the circumstances, an alternative treatment using fiberglass-reinforced prosthesis was explained to her and she agreed for the same and the procedure was carried out.

At first, the shade selection of the acrylic pontic was done. The acrylic pontic was trimmed and adjusted so that, it fit properly in the edentulous space. Pontic was held in place with the help of modeling wax and patient was shown how the bridge will look, if proceeded further. After this, a 3-mm-wide lingual channel on the adjacent teeth of the missing tooth as well as pontic was prepared. The length of the glass fiber was measured and cut. A trial of glass fiber length was taken. The etchant was applied for 30 seconds on the lingual channel of teeth. Then bonding agent was applied and cured. After this, flowable composite was applied and cut fiberglass was placed in the channel and when they were fully embedded in the flowable composite, a thin layer of flowable composite was flown over it and light cured. Successful chemical between fiber framework and pontic was achieved. This contoured and curved complete prosthesis was finished and polished (Figs 1 to $\mathrm{C}$ ).

\section{Case 2}

A male patient aged 30 years reported to the Nagpur Government Dental College and Hospital with the complaint of missing 21 and wanted immediate replacement with conservative approach. Also, in this case, the same fiber-reinforced composite treatment was carried out using acrylic pontic (Figs 2A and B).

\section{Case 3}

A girl aged 18 years reported to the Nagpur Government Dental College and Hospital. She had met with an accident 4 months earlier and had in hairline upper jaw fracture, resulting in the loss of her upper anterior tooth. Treatment for hairline upper jaw fracture was completed but no treatment was taken for lost upper anterior tooth. She had preserved her exfoliated tooth in milk from the time of her accident and it had its original color. For esthetics, she insisted to have her own natural tooth in its original place.

The avulsed tooth of the patient preserved in milk was cut into two parts. The coronal part which was to be restored was contoured according to clinical length of adjacent tooth and gingival contour of socket mimicking natural tooth.

The whole pulp was extirpated from the coronal portion of the tooth, which was to be placed over socket, and pulp chamber was filled with flowable composite and cured for 60 seconds and thus the tooth was ready for replacement of missing 11 region. Horizontal slot was prepared extraorally keeping depth of the slot $1 \mathrm{~mm}$. Then, the prepared avulsed tooth was placed over the edentulous healed socket in 11 region, their combined length was measured and the fiberglass material was cut up to this measured length. The prepared horizontal slot was thoroughly cleaned and dried. It was etched with
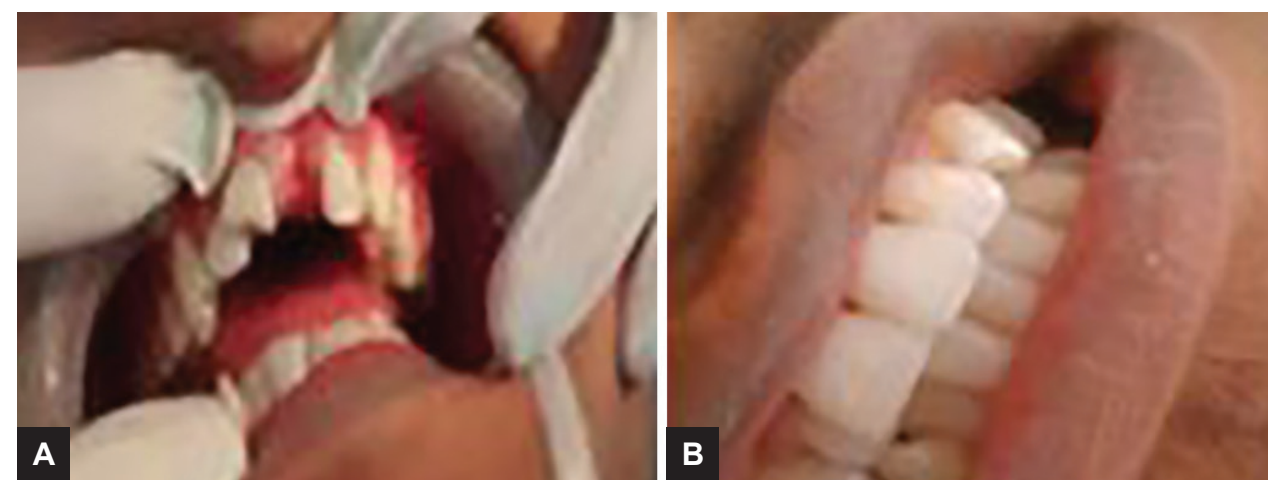

Figs 2A and B: (A) Before treatment; and $(B)$ after treatment 

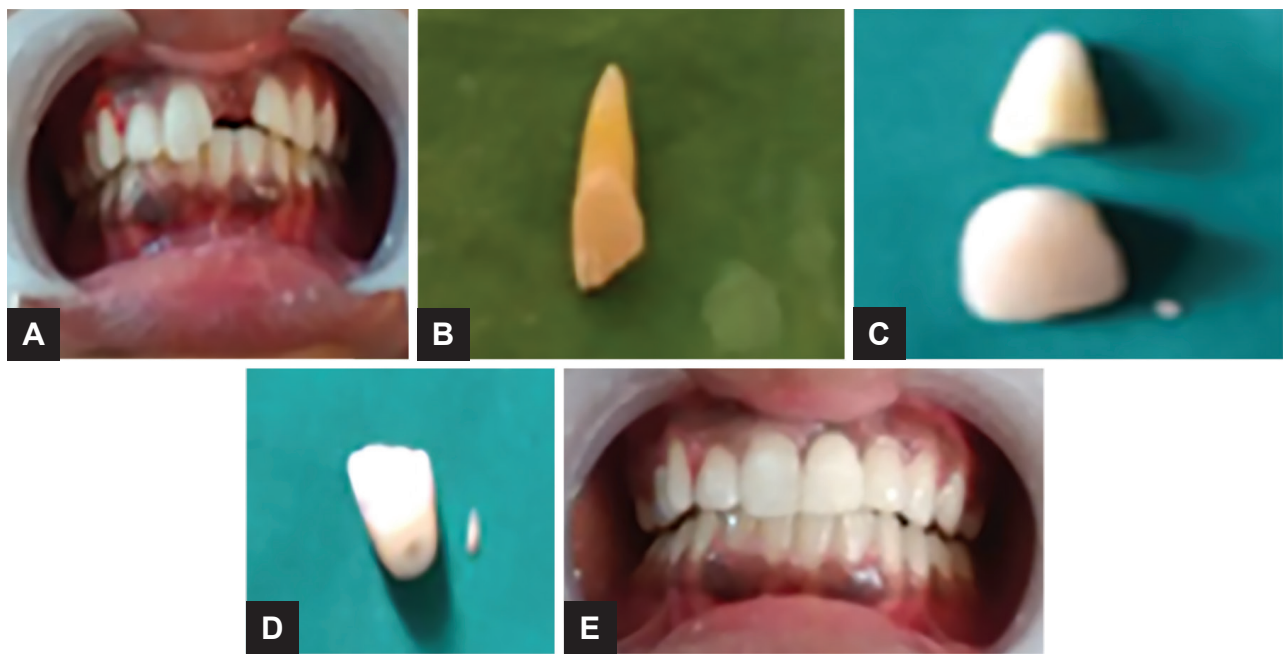

Figs 3A to E: (A) Before treatment; $(B)$ avulsed tooth; $(C)$ root and coronal part of the avulsed tooth; (D) coronal partl and $(E)$ after treatment

etchant containing 37\% phosphoric acid. After rinsing and drying, a thin layer of bonding agent was applied to the prepared slot and cured for 60 seconds. In a completely dry field, flowable composite was flown up to half the depth of the slot. Measured fiberglass materials were placed and pushed into already placed flowable composite. Again the flowable composite was flowed and cured for 60 seconds (Figs $3 \mathrm{~A}$ to $\mathrm{E}$ ).

\section{DISCUSSION}

Single tooth replacement in the anterior region presents a challenge for the clinician. In this region, treatment consideration includes shape and shade matching of the crown, interdental spacing, topography of the ridge, contacts of the opposing tooth, parafunctional habits, and esthetic desire of the patient. Various treatment options can be considered $^{5}$ for the replacement of missing permanent incisor. For many years, the fixed dental prosthesis has been the treatment of choice. However, it requires aggressive tooth reduction, which may increase the possibility of endodontic treatments. The development of implantsupported prosthesis has enabled a more conservative approach. However, the need for surgical procedures and its high cost may reduce the accessibility for some patients.

In the last decade, fiber-reinforced composite was suggested as an alternate material for restoration. ${ }^{6,7}$ In comparison with conventional FPD, this glass fiber-reinforced composite material offers a restorative alternative that produces minimally invasive, esthetic, and cost-effective metal-free tooth replacement. Saving of time, ease of application, absence of metal allergy, and ease of cleaning are other advantages of this technique.

Moreover, the use of glass fiber framework can potentially overcome the problem of debonding of composite luting cement to the frame of resin-bonded
FPD and esthetic liability of the underlying cast material framework.

\section{CONCLUSION}

- The natural esthetic appearance, conservative treatment, and inherent adhesive nature make the fiber-reinforced prosthesis a successful fixed tooth replacement.

- Because of conservative preparation and bonded nature, retention is never as strong as conventional treatment.

- Clinical studies are in progress to determine the efficacy of fiber-reinforced composite fixed prosthesis as a long-term tooth replacement.

\section{REFERENCES}

1. Rosentritt KC, Behr M, Lang M, Handel G. In vitro examination of the fracture strength of three different fiber reinforced composite and one all ceramic posterior inlay fixed partial denture system. J Prosthodont 2002;11:248-253.

2. Rappelli G, Coccia E. Fiber reinforced composite fixed partial denture to restore missing posterior teeth, a case report. J Contemp Dent Pract 2005;6:168-177.

3. Strassler HE, Seno FG. Stabalization of natural dentition in periodontal cases using adhesive restorative materials. Periodont Insights 1997;4:41-45.

4. Rosenstial, SF.; Land, MF.; Fujimoto, J. Contemporary fixed prosthodontics. 4th ed. Mosby Elsevier; 2006.

5. Karman AI, Kir N, Belli S. Four applications of reinforced polyethylene fiber material in orthodontic practice. Am J Orthod Dentofacial Orthop 2002 Jun;121(6):650-654.

6. Mete JJ, Dange SP, Khalikar AN, Vaidya SP. Rehabilitation of anterior dentulous space by glass fiber reinforced composite removable partial denture during preadolescent period. J Indian Prosthodont Soc 2011 Sep;11(3):195-198.

7. Karaarslan ES, Ertas E. Conservative approach for restoring posterior missing tooth with fiber reinforcement material, four clinical reports. Eur J Dent 2011 Oct;5(4):465-471. 
